\title{
Analysis of Water Absorption of Different Natural Fibers
}

\author{
Hosne Ara Begum, Tanima Rahman Tanni, Md Abul Shahid \\ Department of Yarn Engineering, Bangladesh University of Textiles, Dhaka, Bangladesh \\ Email: hosneara@butex.edu.bd
}

How to cite this paper: Begum, H.A., Tanni, T.R. and Shahid, M.A. (2021) Analysis of Water Absorption of Different Natural Fibers. Journal of Textile Science and Technology, 7, 152-160.

https://doi.org/10.4236/jtst.2021.74013

Received: September 3, 2021

Accepted: November 1, 2021

Published: November 4, 2021

Copyright $\odot 2021$ by author(s) and Scientific Research Publishing Inc. This work is licensed under the Creative Commons Attribution-NonCommercial International License (CC BY-NC 4.0). http://creativecommons.org/licenses/by-nc/4.0/

\section{(c) (i) (8) Open Access}

\begin{abstract}
The demand for natural fibers has always been high due to their unique characteristics like strength, lightweight, availability, bio-degradability, etc. In every phase of life, from clothing to technical textiles, natural fibers are used. Water absorption of fibers is considered really important in many aspects, e.g., Sportech, Medtech, Geotech, etc. This work analyses water absorption of raw and alkali-treated cotton, arecas, pineapple leaves, and banana fibers. Fibers were scoured with different concentrations of alkali $(2,4,6 \mathrm{gm} / \mathrm{L} \mathrm{NaOH})$, washed and neutralized with the dilute acetic acid solution, then dried. Later on, the fiber samples were immersed into distilled water, and water absorption percentages of the fibers were determined every 10 minutes within 1 hour in total. It appeared that at untreated conditions, the areca fiber has the highest water absorption capacity compared to the other fibers. Alkali-treated cotton shows the highest water absorption, and areca fibers show approximately $60 \%$ water absorption of cotton.
\end{abstract}

\section{Keywords}

Water Absorption, Alkali Treatment, Areca Nut Husk Fiber, Pine Apple Leaf Fiber, Banana Fiber

\section{Introduction}

This work aimed to determine the water absorption characteristics of different natural fibers: banana fibers, Pineapple Leaf Fibers (PALF), and areca nut husk fibers, at raw and alkali-treated conditions to assess their suitable application areas with the feeling of expectation that the three latter mentioned fibers might rival the textile giant, cotton, with increased water absorption property. The reason behind this expectation was the surface study of the fibers.

Natural fibers are in great demand in today's world because of their superior properties. Water absorption is one of the most important properties of textile 
fibers, which determines comfort, strength, elongation, and many other fabric or end-product properties. Researchers have been looking for natural replacements of synthetic fibers, which will be easily available, green, renewable, and sustainable resources at the same time. Areca fibers, Pine Apple Leaf fibers (PALF), and banana fibers are three natural vegetable fibers that have a great prospect and potential in the textile field. Banana, areca, and pineapple are widely grown agricultural commodities of Bangladesh. The banana plant stems, areca nut husks, and pineapple leaves are considered agro-wastes here, and the proper disposal facility of these huge amounts of waste is neither adequate nor practiced. These items are easily available in good amounts, and most importantly, they can provide natural textile fibers rich in cellulose. Therefore, these three fibers have generated interest for performing this work. Cotton has been used as a reference or standard to compare with.

Fibers from cottonseeds, areca nut husks, pineapple leaves, and banana pseudostems are cellulosic fibers and contain a very good amount of cellulose in their structures. To be specific, in cotton fibers $80 \%-94 \%$, in areca fibers $53.20 \%$, in pineapple leaf fibers $67 \%-81 \%$, and in banana fibers $65.112 \%$, which has been mentioned in Table 1 . The constituents of these fibers, especially the cellulose being glucose, have hydroxyl groups (-OH). The presence of hydroxyl makes them a polar group, which is liable for water absorption. The cellulose content in fiber positively influences the water absorption, whereas the outer layer of natural oil, wax, and fat hinder water molecules from penetrating inside the fiber. Hence, $\mathrm{NaOH}$ treatment was done on each of the fiber samples with different concentrations in this work.

Water absorption leads to swelling of the fiber. Natural fibers are prone to water absorption due to their chemical composition rich in cellulose, hydrophilic in nature. Water absorption of natural fiber is more likely to increase with the increase in cellulose content of the fiber due to the increase in the number of free hydroxyl groups existing in the fiber. If closely observed, it will be clear that the chemical compositions of the four fibers (which have been given in Table 1) are more or less rich in cellulose, having other components also in their structures.

Cotton is a seed fiber belonging to the genus Gossypium. Cotton can absorb water up to 24 - 27 times its own weight [5]. The fiber is almost pure cellulose and is most often spun into yarn or thread and used to make a soft, breathable textile. Oil, wax, protein, pectin, and some coloring contents are also present in cotton. The standard moisture content of this fiber is $7.34 \%$.

Areca nut or betel nut is the fruit of the Areca palm tree (Areca catechu). The fiber extracted from areca nut is known as Areca Nut Husk Fiber as well as Betel Nut Husk Fiber. Areca nut fruits are divided into three types of maturity levels, i.e., raw, ripe, and matured fruits. From different analyses, it has been seen that areca fiber has a lumen in its cross-section, and the surface is rough and perforated, and porous [6]. Areca fiber is composed of cellulose, hemicellulose, lignin, and pectin at varying compositions. The moisture content of this fiber in the dried condition is $14 \%-16 \%$ [7]. 
Table 1. Chemical composition of cotton fiber, areca fiber, PALF and banana fiber.

\begin{tabular}{|c|c|c|c|c|}
\hline $\begin{array}{ll}\text { Components (\%) } & \text { Fibers } \\
\end{array}$ & Cotton $[1]$ & Areca [2] & PALF [3] & Banana $[4]$ \\
\hline Cellulose & $80-94$ & 53.20 & $67-81$ & 65.112 \\
\hline Hemi cellulose & - & 32.98 & $9-19$ & 17.325 \\
\hline Lignin & - & 07.20 & $4-15$ & 08.018 \\
\hline Oil \& wax & $0.5-0.1$ & 00.64 & $3-4$ & 02.502 \\
\hline Ash & $0-1$ & 01.05 & $0.9-3$ & - \\
\hline Pectin & $0-1.5$ & - & $1-3$ & 02.124 \\
\hline Mineral \& other matters & $1-1.5$ & 03.12 & - & 04.919 \\
\hline
\end{tabular}

The tropical perennial pineapple is a member of the family Bromeliaceae. The quality of pineapple, which is used for fiber extraction, is different from what is grown as a fruit. It is white, creamy, and lustrous as silk fiber and is 10 times as coarse as cotton but as fine as jute with well-separated filaments [1]. Pineapple fiber extraction can be done both manually and mechanically. PALF consists of high cellulose content, a large amount of hemicellulose, and some lignin, too. The moisture content of this fiber is $10 \%-11 \%$ [8].

Banana fiber, a lignocellulosic natural bast fiber, is obtained from the pseudostem of the banana plant belonging to the genus Musa. Its physical appearance is similar to ramie fiber. It is mainly composed of cellulose, hemicelluloses, lignin, etc. The moisture content of this fiber is $10 \%-11.5 \%$ [9].

The water absorption property of the above-mentioned fibers has been focused on in this study.

\section{Material \& Methods}

\subsection{Materials}

Cotton fiber, areca fiber, PALF, and banana fiber are the raw materials for this study. These fibers were collected from villages nearby Dhaka and conditioned in standard atmospheric conditions for 24 hours. No other treatment was performed on the fibers before conditioning. After conditioning, scouring was done. Chemical components used for scouring were sequestering agents (Optavon Mex Liq) to remove the hardness of water, wetting agent (Imerol PCLF), and detergent (Hasulyn NOF) to lower the surface tension of water, $\mathrm{NaOH}$ for scouring, and distilled water. Acetic acid was used for neutralization. Electric balance, rotadyer, oven dryer, test tubes, beakers, glass rod, $\mathrm{pH}$ paper, filter paper, etc., were needed.

\subsection{Methods}

The fibers were prepared for water absorption by the alkali treatment process, which included scouring of the fibers, rinsing, neutralization, and finally drying, which has been shown in Figure 1. Then water absorption was measured. 


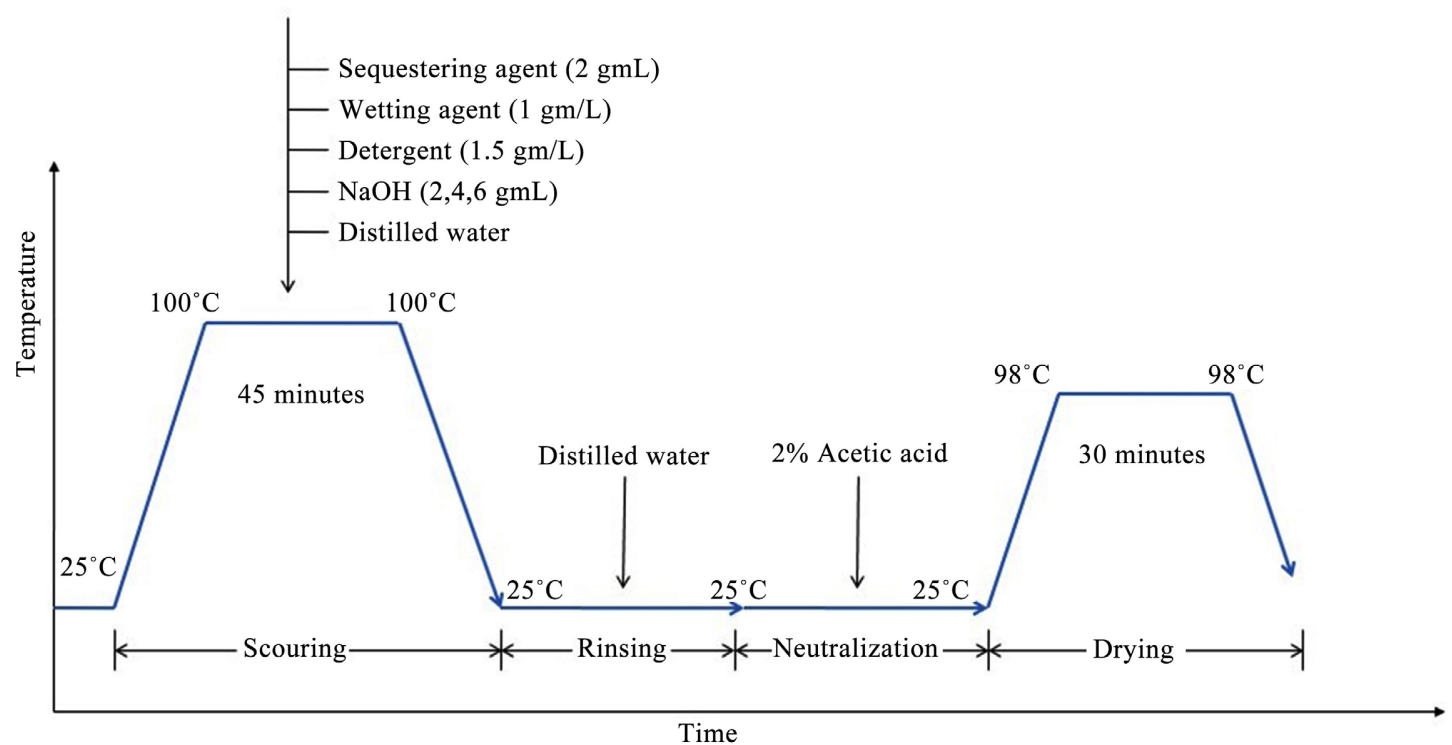

Figure 1. Alkali treatment process.

\subsubsection{Scouring}

After collecting and conditioning, three samples (each weighting $10 \mathrm{gm}$ ) were made for each of the four fibers. Scouring liquor was prepared with the sequestering agent, wetting agent, detergent, $\mathrm{NaOH}$, and distilled water as per concentration shown in Figure 1, and samples were then scoured. $\mathrm{pH} 8$ - 9 was maintained in the whole process and was checked using $\mathrm{pH}$ paper.

\subsubsection{Drying}

The scoured fiber samples were placed inside the oven dryer for 1 hour at $98^{\circ} \mathrm{C}$ to dry the excess water out of the fibers. After the fibers had been taken out of the drier, they were kept at standard atmosphere for 24 hours for conditioning.

\subsubsection{Water Absorption Measurement}

Scoured samples were immersed in separate containers filled with distilled water for 10 minutes time intervals within 1 hour at room temperature. For this process, each sample size was 5 grams. After every specific time interval (every 10 minutes), samples were taken out of the container; the fiber samples were kept between a pair of filter papers and a pair of circular disks, each weighting 15 grams (as shown in Figure 2). As a result, the filter paper absorbed their surface moisture and by the pressure of one circular disk weighting 15 grams. Then sample weights were taken using a precise digital balance machine to calculate water absorption percentages of the samples.

Water Absorption $\%=\frac{\text { weight after immersion }- \text { weight before immersion }}{\text { weight before immersion }} \times 100 \%$

\section{Result}

\subsection{Water Absorption \% of the Raw Natural Fibers}

If Figure 3 is closely observed, it can be seen that water absorption of cotton is 


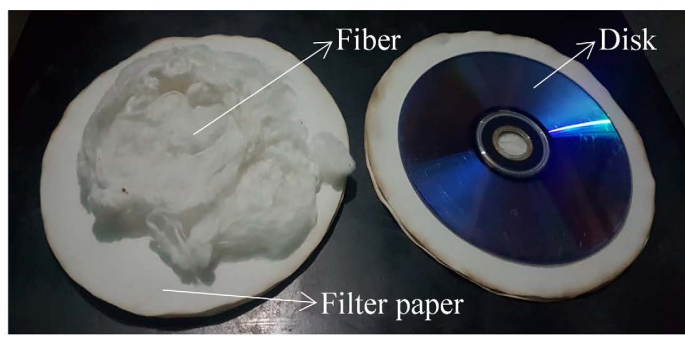

(a)

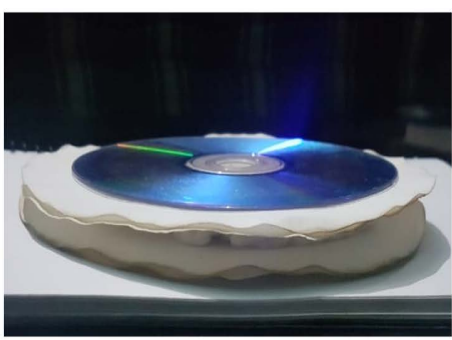

(b)

Figure 2. (a) Fiber position on filter paper; (b) Surface water absorption by filter paper.

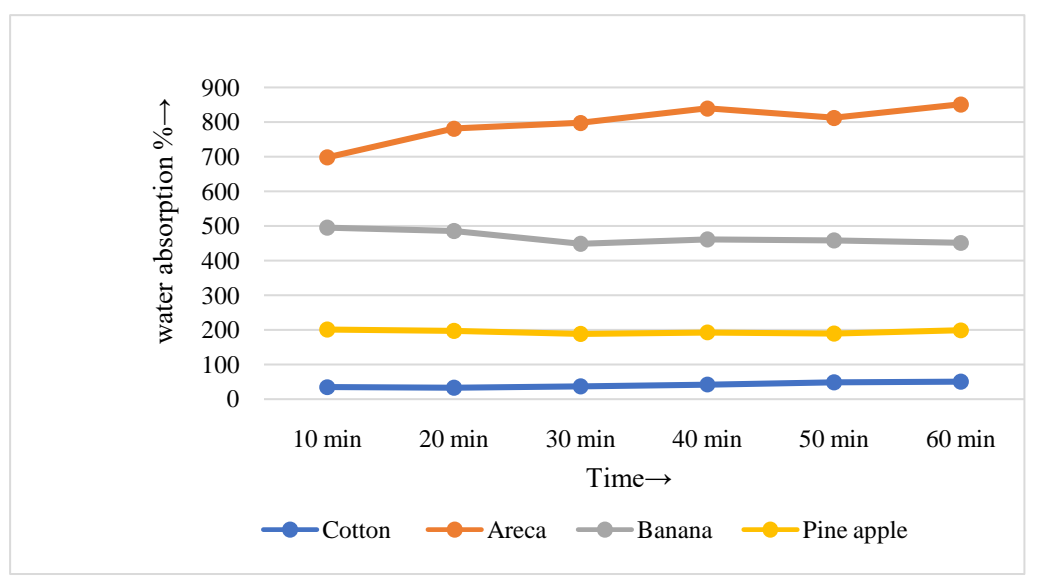

Figure 3. Water absorption \% of raw fibers.

wavering between $32.5 \%$ to $50.5 \%$. Water absorption of PALF wavers from $188 \%$ to $201 \%$, banana fiber from $495 \%$ to $448.5 \%$. Water absorption of raw areca fiber remains from $698 \%$ to $851 \%$.

\subsection{Water Absorption \% of the Alkali Treated Natural Fibers}

\subsubsection{Effect of $2 \mathrm{gm} / \mathrm{L}$ Alkali Treatment on Water Absorption \% of the Natural Fibers}

In the case of $2 \mathrm{gm} / \mathrm{L}$ alkali treatment shown in Figure 4, water absorption of cotton fiber is the highest at each time interval. At 10 minutes, water absorption is about $1200 \%$. As time goes, water absorption keeps on reducing. Then it maintains almost a flat line indicating very little change. The water absorption diagram of areca fiber starts with $631 \%$ and keeps on changing direction in an up and down fashion. Similar is the case of banana fiber, but it starts with $480 \%$ water absorption. PALF starts with $211.5 \%$ water absorption and shows a little change in water absorption; hence diagram remains almost flat within the whole work.

\subsubsection{Effect of $4 \mathrm{gm} / \mathrm{L}$ Alkali Treatment on Water Absorption \% of the Natural Fibers}

In the case of $4 \mathrm{gm} / \mathrm{L}$ alkali treatment shown in Figure 5, cotton fiber shows the highest water absorption, too. Just like $2 \mathrm{gm} / \mathrm{L}$ alkali treatment, after cotton comes areca fiber, then banana fiber, and PALF sequentially. Areca fiber diagram still remains the same, starting with 519\% water absorption; the graph slightly in- 
creased and then slightly decreased and continued in this manner. Banana fiber and PALF diagrams overlap each other after 20 minutes.

\subsubsection{Effect of $6 \mathrm{gm} / \mathrm{L}$ Alkali Treatment on Water Absorption \% of the Natural Fibers}

In the case of $6 \mathrm{gm} / \mathrm{L}$ alkali treatment shown in Figure 6, again cotton fiber shows the highest water absorption. Next to that comes areca fiber, banana fiber, and PALF consecutively. Areca fiber's diagram starts with $540 \%$ water absorption, banana fiber with 394\%, and PALF with 249\%. After 50 minutes, banana fiber and PALF diagrams cross each other, and a slight change in their directions is seen.

To put it briefly, in alkali-treated conditions, water absorption of cotton fiber wavers from $890 \%$ to $1165.5 \%$, areca fiber from $417.5 \%$ to $631 \%$, banana between $248.5 \%$ to $480 \%$, and PALF $175 \%$ to $300.5 \%$. So, it can be said that for any concentration $(2,4$, or $6 \mathrm{gm} / \mathrm{L} \mathrm{NaOH})$ of alkali treatment (Figures 4-6), cotton shows the highest water absorption than other fibers. Just after cotton comes areca fiber. Then come banana and PALF. Banana fiber and PALF diagrams seem to show a similar attitude.

The summary of the results has been displayed in Table 2 .

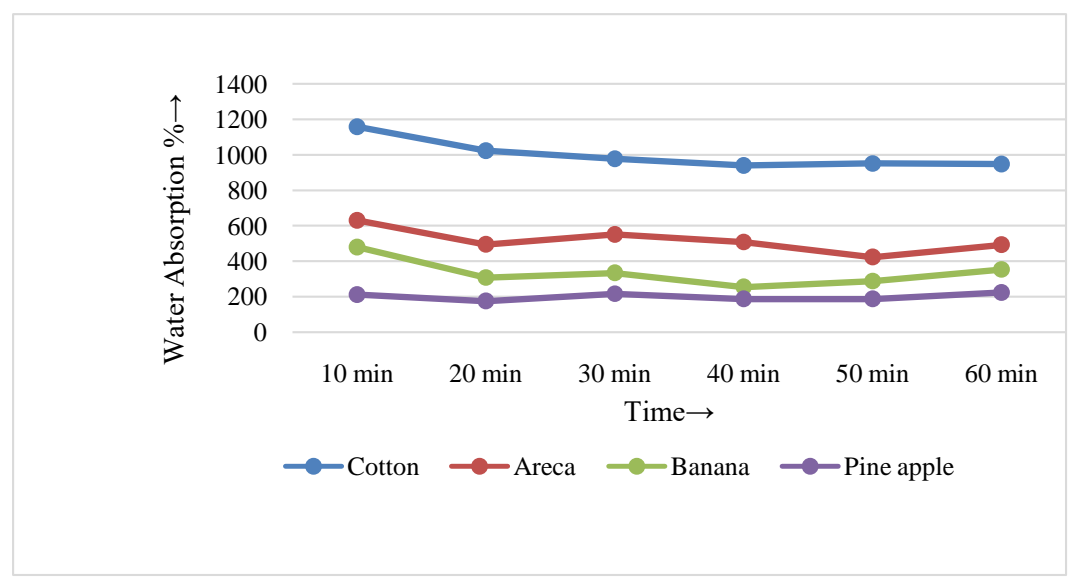

Figure 4. Water absorption $\%$ of $\mathrm{NaOH}(2 \mathrm{gm} / \mathrm{L})$ treated fibers.

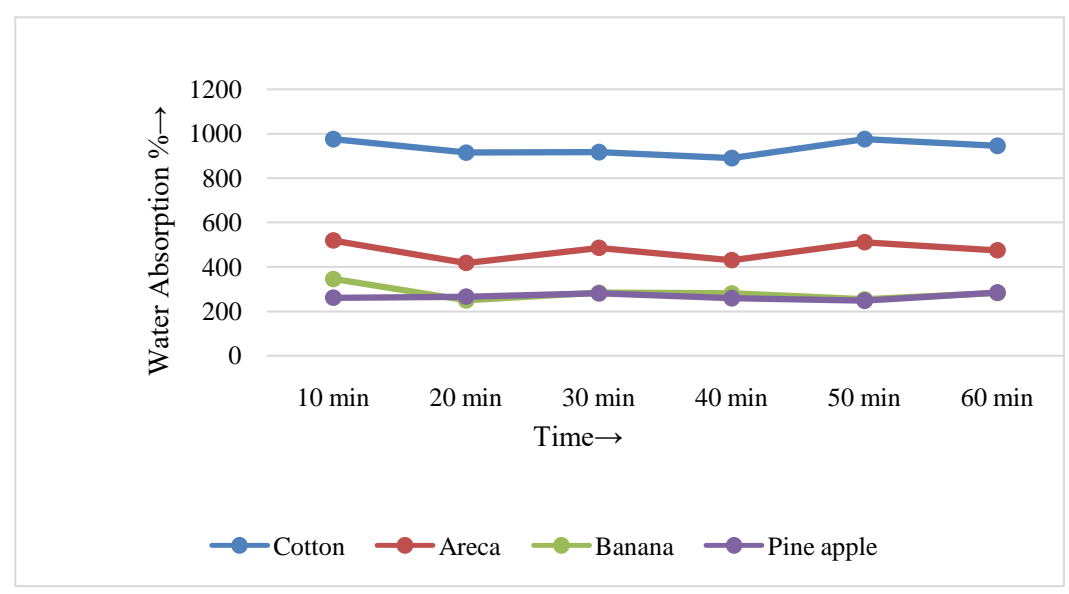

Figure 5. Water absorption $\%$ of $\mathrm{NaOH}(4 \mathrm{gm} / \mathrm{L})$ treated fibers. 


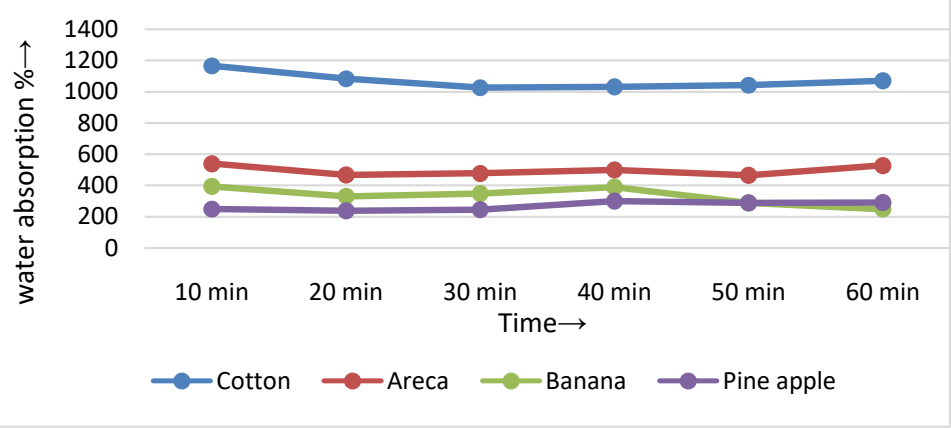

Figure 6. Water absorption \% of $\mathrm{NaOH}(6 \mathrm{gm} / \mathrm{L})$ treated fibers.

Table 2. Water absorption percentages obtained in the experiment.

\begin{tabular}{ccc}
\hline Fibers & $\begin{array}{c}\text { Water absorption } \\
\text { of raw fibers }\end{array}$ & $\begin{array}{c}\text { Water absorption of alkali } \\
(2,4 \text { \& } 6 \text { gm/L) treated fibers }\end{array}$ \\
\hline Cotton & $32.5 \%$ to $50.5 \%$ & $890 \%$ to $1165.5 \%$ \\
Areca & $698 \%$ to $851 \%$ & $417.5 \%$ to $631 \%$ \\
Banana & $495 \%$ to $448.5 \%$ & $248.5 \%$ to $480 \%$ \\
Pineapple & $188 \%$ to $201 \%$ & $175 \%$ to $300.5 \%$ \\
\hline
\end{tabular}

\section{Discussions}

\subsection{Water Absorption \% of the Raw Natural Fibers}

It can be seen that water absorption is the least in the case of cotton. The most possible reason behind this is that cotton fiber is coated with natural oil and wax to such an extent that it hardly can uptake any water; it behaves completely hydrophobic in its raw state. Raw PALF and banana fiber show higher water absorption than untreated cotton. This may be because of the less amount of oil and wax present in them than cotton, as well as due to the removal of hydrophobic lignin from their fiber structure and the presence of unaffected hydrophilic hemicellulose in their structure. Among the four fibers, raw areca fiber acts completely different regarding water absorption; the highest. It may be due to the presence of a lot of pores both on the surface and inside the fiber structure, which can hold water molecules inside the space even in an untreated condition. Another reason is that areca fiber contains the highest amount of hemicellulose among the four fibers.

\subsection{Effect of 2, 4, and $6 \mathrm{gm} / \mathrm{L}$ Alkali Treatment on Water Absorption \% of the Natural Fibers}

Alkali-treated cotton shows the highest water absorption than other fibers. This may be due to the increased removal of oil and wax from the cotton fiber surface, which allows the fiber to absorb more water. However, cotton cellulose has not been affected by any of the concentrations 2,4 , or $6 \mathrm{gm} / \mathrm{L} \mathrm{NaOH}$. So, it could easily absorb water. Alkali treated areca fiber comes in second place, showing less 
water absorption, about $60 \%$ of the cotton fiber. The reason behind the reduced water absorption capacity of treated areca fiber, PALF, and banana fiber than untreated state might be the removal of hemicellulose from their structures to some extent.

Water is a strong polar compound, and it is easily attracted by the polar -OH groups of all cellulosic fibers. But the outer layer of cotton fiber is oil and wax, which does not let the water molecules enter into the cotton polymer. Cotton fiber remains unaffected and undamaged in alkali solution, and alkali treatment can clear the waxy layer efficiently. So, cotton is supposed to withstand different alkali concentrations without affecting the cellulose, which absorbs water.

Major portions of areca fiber, PALF, and banana fiber are composed of cellulose, hemicellulose, and lignin. Oil, wax, and pectin are also present in a small amount. Cellulose and hemicellulose are responsible for the water absorption of the fibers, whereas lignin, oil, wax, and pectin are hydrophobic in nature. Alkali treatment leads to the removal of oil and wax, and an increased amount of alkali concentration breaks down lignin. So, the relative percentages of hydrophobic components are decreasing. Therefore, an increased accessibility to the surface of fiber can be expected. Hemi-cellulose of areca, PALF, and banana fiber is also affected to some extent by increased alkali concentration.

Here one thing puts the claim to be clarified that the test results do not necessarily have any link with the standard moisture content of the fibers. The ratio of the mass of moisture in a material to the total moist mass is called its moisture content which is an inherent property of the fibers. When materials are kept in the environment, they slowly absorb moisture from the air in order to go into an environmental equilibrium. However, in this work, the assessment of water absorption has been carried out by dipping or immersing the fibers into the water, and after a certain time, the amount of water absorption is only calculated. This absorption occurred in direct contact with water.

Finally, a recommendation may be put forward from the findings that areca fiber has a significant water absorption percentage and may be used in technical textiles due to its porous construction, especially in the untreated stage. As water absorption percentages of banana fiber and PALF are lower, they may be used where water absorption is required at comparatively lower levels.

\section{Conclusion}

In this work, water absorption percentages of four natural fibers: cotton fibers, areca fibers, PALF, and banana fibers have been studied. It appears that at untreated conditions, areca fibers have the highest water absorption capacity. Then come banana fibers, PALF, and cotton fibers consecutively. After scouring with different concentrations of alkali, cotton shows the highest water absorption percentage among the four fibers. Alkali-treated areca fibers show less water absorption than cotton, which is more than fifty percent of cotton fibers. Alkali-treated PALF and Banana fibers show quite similar behavior. Their water absorption percentages are lower than cotton fibers and areca fibers. The porous structure of 
areca fiber and its water absorption behavior can be an asset to the technical textiles sector. At the same time, PALF and banana fibers can also be the center of attention in the field where less water absorption is required. The result of this study may grow interest among researchers to find out suitable application areas of these fibers and may favor further researches in the future.

\section{Acknowledgements}

The authors are extremely thankful to Micro Fiber Group and Textile Testing \& Quality Control Laboratory and Wet Processing Laboratory of the Bangladesh University of Textiles for their co-operation and selfless support to conduct the work.

\section{Conflicts of Interest}

The authors declare no conflicts of interest regarding the publication of this paper.

\section{References}

[1] Siddique, A.B., and Begum, H.A. (2016) Natural Fibers (Textile Raw Materials-1). Book Fairs Publication, Dhaka.

[2] Steadman, R. (1970) Materials Science. Physics Education, 5, 70-71. https://doi.org/10.1088/0031-9120/5/2/304

[3] Yahya, S.A.B. and Yusof, Y. (2013) Comprehensive Review on the Utilization of PALF. Advanced Materials Research, 701, 430-434. https://doi.org/10.4028/www.scientific.net/AMR.701.430

[4] Rashid, M., Samad, S.A., Gafur, M.A. and Chowdhury, A.M.S. (2015) Study of Different Chemical Treatments for the Suitability of Banana (Musa oranta) Fiber in Composite Materials. International Journal of Scientific \& Engineering Research, 6, 1870-1875. https://doi.org/10.14299/ijser.2015.04.006

[5] Ravandi, S.A.H. and Valizadeh, M. (2011) Properties of Fibers and Fabrics that Contribute to Human Comfort. Elsevier, Masson.

[6] Yusriah, L., Sapuan, S.M., Zainudin, E.S. and Mariatti, M. (2012) Exploring the Potential of Betel Nut Husk Fiber as Reinforcement in Polymer Composites: Effect of Fiber Maturity. Procedia Chemistry, 4, 87-94. https://doi.org/10.1016/j.proche.2012.06.013

[7] Begum, H.A., Saha, S.K., Siddique, A.B. and Stegmaier, T. (2019) Investigation on the Spinability of Fine Areca Fiber. The Journal of the Textile Institute, 110, 1241-1245. https://doi.org/10.1080/00405000.2018.1559017

[8] Mittal, M. and Chaudhary, R. (2018) Experimental Study on the Water Absorption and Surface Characteristics of Alkali Treated Pineapple Leaf Fibre and Coconut Husk Fibre. International Journal of Applied Engineering Research, 13, 12237-12243.

[9] Jatti, K., Vaishnav, P. and Titiksh, A. (2016) Evaluating the Performance of Hybrid Fiber Reinforced Concrete Dosed with Polyvinyl Alcohol. International Journal of Trend in Research and Development, 3, 354-357. 